\title{
UPAYA PEMANFAATAN LIMBAH PENGOLAHAN KELAPA MELALUI TEKNOLOGI PEMBUATAN NATA DE COCO PADA KWT BENGKE SAKATO DI KABUPATEN PADANG PARIAMAN
}

\author{
Wenny Surya Murtius")., Novizar, Rini, Neswati, Deivy Andhika Permata \\ dan Viony Derosya \\ Jurusan Teknologi Hasil Pertanian, Fakultas Teknologi Pertanian, Universitas Andalas, \\ ") Email : wenny.murtius@gmail.com
}

\begin{abstract}
ABSTRAK
KWT Bengke Sakato merupakan salah satu kelompok tani pada Jorong Bengke di Kecamatan VII Koto Sungai Sariak Kabupaten Padang Pariaman dengan anggota terdiri dari ibu-ibu yang aktif. KWT ini aktif bergerak di bidang pengolahan kelapa, diantara produk yang dihasilkan adalah minyak kelapa dan VCO (Virgine Coconut Oil). Salah satu produk kelapa yang mereka jual kepada pembuat arang batok kelapa adalah sabut dan tempurung. Namun selama ini air kelapa sampai belum dimanfaatkan dan masih menjadi limbah. Pada kegiatan ini akan diangkat untuk memanfaatkan limbah yang ada, agar bernilai ekonomi dan menjadi pendapatan baru bagi anggota kelompok. Kegiatan ini akan dilakukan melalui beberapa tahap diantaranya: sosialisasi, penyuluhan, pengolahan (praktek langsung bersama mitra), pendampingan dan evaluasi. Dari hasil kegiatan terlihat antusiasme peserta sangat tinggi kegiatan yang dilaksanakan sehingga diharapkan dari kegiatan produksi ini bisa berlanjutan.
\end{abstract}

Kata Kunci: pemberdayaan, KWT bengke sakato, kelapa, nata de coco

\section{Development of Nata De Coco in Bengke Sakato KWT in Padang Pariaman District as an Efforts to use Coconut Processing Waste}

\begin{abstract}
KWT Bengke Sakato is a farmer group consisting of active mothers from Jorong Bengke District VII Koto Sungai Sariak, Padang Pariaman Regency. KWT is actively engaged in coconut processing, among the products produced are coconut oil and VCO (Virgine Coconut Oil). Coir and coconut shell they sell to coconut shell charcoal makers. But coconut water until before it was implemented by IbDM is still a waste (just thrown away). So that the IbDM program was appointed to utilize existing waste, to be of economic value and become a new income for group members. The program is delivered through several stages, including: socialization, counseling, processing (direct practice with partners), mentoring and evaluation. The enthusiasm of the participants was very high at the time of programming, so it was hoped that production activities could continue
\end{abstract}

Keywords : empowerment, KWT bengke sakato, coconut, nata de coco

\section{PENDAHULUAN}

Kabupaten Padang Pariaman sudah sangat terkenal sebagai sentra perkebunan kelapa di Sumatera Barat, dengan tanaman kelapa yang menyebar di setiap wilayah. Salah satu sentra tanaman kelapa dan pengolahan kelapa yang terdapat di Kabupaten Padang Pariaman adalah Kecamatan VII Koto Sungai Sariak. Kecamatan VII Koto Sungai Sariak memiliki luas areal tanaman kelapa 2.549 Ha dengan produksi 2.149 ton/th. Memiliki 6 nagari, salah satunya Nagari Ambuang Kapau (Pemekaran dari Nagari Sungai Sariak) (BPS, 2017). Dengan luas lahan tanaman kelapa, di Kecamatan 
VII Koto Sungai Sariak juga terdapat industri pengolahan kelapa: baik kopra, arang batok, minyak kelapa (minyak tanak) dan juga VCO. Kesemua pengolahan kelapa tersebut sudah pasti menghasilkan air kelapa.

Sebagai daerah yang mengalami kerusakan cukup parah pada gempa 30 september 2009 lalu, perekonomian masyarakat belum sepenuhnya pulih. Akan tetapi dengan berbagai bantuan kemanusian dalam bentuk keterampilan dan motivasi hidup yang didapat dari para relawan saat itu, menjadikan masyarakat yang bersemangat dan selalu ingin maju. Sehingga setiap kegiatan yang dilaksanakan, sering kali sukses dilaksanakan dan berkelanjutan.

Kelompok Wanita Tani (KWT) Bengke Sakato merupakan KWT yang aktif dalam pengolahan kelapa, dimana KWT ini sudah memproduksi minyak kelapa dan VCO, disamping itu juga sebagai pemasok batok untuk industri arang batok kelapa yang juga terdapat di Nagari Ambuang Kapau. KWT yang berdiri tahun 2013 ini diketuai oleh Ibu Ermatius (47 th), beranggotakan 16 orang Ibu-ibu yang aktif. Produksi minyak kelapa dan VCO KWT ini yang sudah dilakukan secara terus menerus dan berkelanjutan, menjadikan produksi air kelapa yang juga berlimpah. Dimana selama ini air kelapa yang mereka hasilkan dibuang begitu saja (belum termanfaatkan).

Produksi air kelapa yang berlimpah mendorong KWT ini untuk dapat memanfaatkannya menjadi produk yang bernilai ekonomi. Sehingga KWT ini dalam suatu pertemuan dengan pengusul di Kantor Dinas Pertanian setempat menyampaikan niatnya kepada pengusul, untuk dapat diberi bimbingan untuk seluruh anggota KWT dalam pembuatan Nata de coco, dengan harapan setelah dilakukan kegiatan tersebut air kelapa yang mereka hasilkan tidak lagi terbuang percuma. Hidayat, Padaga dan Suhartini (2006) menyatakan Nata de coco merupakan minuman dengan isian nata berbentuk persegi dengan warna putih bersih, kenyal jika digigit dan berupa selulosa. Nata de coco ini biasanya disajikan dalam syrup dengan berbagai rasa. Nata de coco dihasilkan dari metabolisme bakteri Acetobakter xylinum, atau sebagai metabolit sekundernya. Dalam produksinya, bakteri ini membutuhkan gula sebagai sumber Carbon dan bahan lain sebagai sumber Nitrogen.

Umumnya senyawa dengan karbohidrat sederhana dapat digunakan sebagai sumber carbon dalam pembuatan nata, seperti maltosa, sukrosa, laktosa, glukosa, mannosa dan fruktosa. Namun agar biaya produksi tidak terlalu besar, maka sukrosa merupakan yang paling ekonomis digunakan dan cocok untuk pertumbuhan bakteri nata yaitu Acetobacter xylinum. Nata terbuat dari campuran beberapa media, karena Acetobacter xylinum membutuhkan carbon, asam organik dan mineral (Pambayun, 2002).

Organisasi wanita merupakan sumber daya yang sangat layak untuk ditingkatkan keterampilannya, sehingga mereka bisa membantu dalam meningkatkan perekonomian keluarga, dengan hanya bekerja dirumah dan memanfaatkan sesuatu yang selama ini dianggab sebagai limbah. Selain itu Ilmu dan keterampilan yang diberikan akan lebih bermanfaat bilaberkaitan langsng dengan sumber daya yang ada, apalagi yang selalu diproduksi dan belum termanfaatkan. 


\section{METODE}

Kegiatan ini telah dilakukan dengan mitra KWT Bengke Sakato di Kabupaten Padang Pariaman. Kegiatan ini bertujuan untuk menyelesaikan permasalahan mitra, maka pendekatan yang ditawarkan adalah: Metode ceramah dan diskusi dalam bentuk Andragogi (metode pembelajaran orang dewasa) yang dilakukan sejalan dengan penyuluhan, menyediakan peralatan dan bahan awal yang dibutuhkan oleh mitra dalam produksi nata de coco, pendampingan dalam pembuatan starter dan nata de coco, setelah kegiatan penyuluhan dan pelatihan selesai dilakukan, maka kelompok mitra akan dibimbing secara berkelanjutan dan dimonitoring secara teratur hingga saat berakhirnya program. Kegiatan praktek pada awalnya dilakukan secara bersama yang bertujuan untuk memudahkan mitra melanjutkan kegiatan setelah pelatihan selesai dilakukan. Pada kesempatan ini seluruh anggota KWT ambil bagian dalam setiap kegiatan.

\section{Penyuluhan}

\section{HASIL DAN PEMBAHASAN}

Penyuluhan merupakan rangkaian dari kegiatan yang dilakukan. Pada kesempatan yang telah disepakati diadakan kegiatan penyuluhan dengan beberapa materi yang telah disepakati. Pada kesempatan ini Prof. Dr. Ir. Novizar Nazir, MSi juga menyampaikan beberapa hal terkait sertifikasi halal. Termasuk hal hal yang memungkinkan sertifikat tidak dikeluarkan, kemudahan dalam pengurusan dan kecurangan yang juga dilakukan oleh produsen menyangkut kehalalan produknya. Sertifikasi halal telah menjadi keharusan pada saat sekarang ini, karena konsumen sudah cendrung untuk menggunakan produk yang memang dengan nyata tercatat pada lembaga yang terjamin dan sudah dikeluarkan sertifikatnya. Hal tersebut dapat meningkatkan nilai dari produk yang dihasilkan. Hal hal yang akan diperikasa diantaranya mengenai bahan baku yang digunakan, peralatan yang digunakan dan kemasan.

Materi lain yang disampaikan adalah mengenai produk turunan lainnya. Selain memanfaatkan limbah pengolahan kelapa seperti air kelapa menjadi nata de coco, produk lain yang mungkin dikembangkan adalah sabun, deterjen, lemak, madu ampas kelapa dan lain sebagainya. Materi ini disampaikan dengan maksud membuka wawasan mitra. Selain produk turunan kelapa lainnya, materi lain yang juga disampaikan adalah mengenai pengembangan produk yang telah dihasilkan seperti minyak kelapa dan vco, termasuk analisa labor dan standar dari masing masing analisa, disampaikan oleh Dr. Ir. Rini, MSi.

\section{Praktek Pembuatan Nata de Coco}

Pelaksanaan praktek diikuti oleh seluruh anggota KWT Bengke Sakato, dimana seluruh peserta memperlihatkan antusiasme yang tinggi pada saat diadakan pelatihan dan praktek. Pada saat praktek dilengkapi dengan kopian bahan yang mendukung praktek, dan ataupun yang bisa dimanfaatkan oleh peserta setelah pelatihan selesai. Pelatihan dimulai dari pembuatan starter, persiapan bahan baku, pembuatan nata de coco dan pembuatan syrup nata de coco. Kemudian diakhiri dengan pengemasan pada cup glass plastic. 


\section{Pengolahan}

Pengolahan yang dilakukan adalah pembuatan nata de coco dengan memanfaatkan limbah air kelapa. Air kelapa yang berlimpah selama ini memang masih menjadi limbah, karena belum diolah dan dimanfaatkan. Nata berasal dari bahasa Spanyol yang artinya terapung apung. Nata bertekstur kenyal, bewarna putih dan sedikit transparan yang terapung apung dalam medium yang mengandung gula. Nata sebenarnya metabolit sekunder dari aktivitas bakteri Acetobacter xylinum, yang merupakan substansi padat yang terbentuk di permukaan medium cair. Apabila dilihat dibawah mikroskop, nata akan tampak sebagai suatu masa fibril yang tidak beraturan seperti benang atau kapas (Sutarminingsih, 2004).

Pemanfaatan air kelapa sebagai bahan baku pembuatan nata de coco, dengan memanfaatkan bakteri Acetobacter xylinum sebagai agent yang memproduksi selulosa yang kemudian tersusun membentuk lembaran nata. Nitrogen merupakan kebutuhan utama bakteri Acetobacter xylinum selain Carbon. Sehingga menyediakan Nitrogen merupakan hal yang penting dalam pembuatan nata de coco. Beberapa sumber Nitrogen yang sering digunakan antara lain adalah yang bersifat tidak food grade atau tidak disarankan untuk pangan, sehigga berkembang beberapa penelitian untuk memanfaatkan sumber nitrogen yang berasal dari bahan pangan, seperti kecambah kacang hijau (toge), ampas kedelai dan lain sebagainya (Nasution, 2006). Pada kesempatan ini digunakan kecambah kacang hijau (toge) sebagai sumber Nitrogen. Toge sebelum digunakan terlebih dahulu dicuci bersih dan dikecilkan ukuran dengan blender. Perbandingan air dan toge adalah 2:1. Gambar 1 berikut sari kecambah kacang hijau.

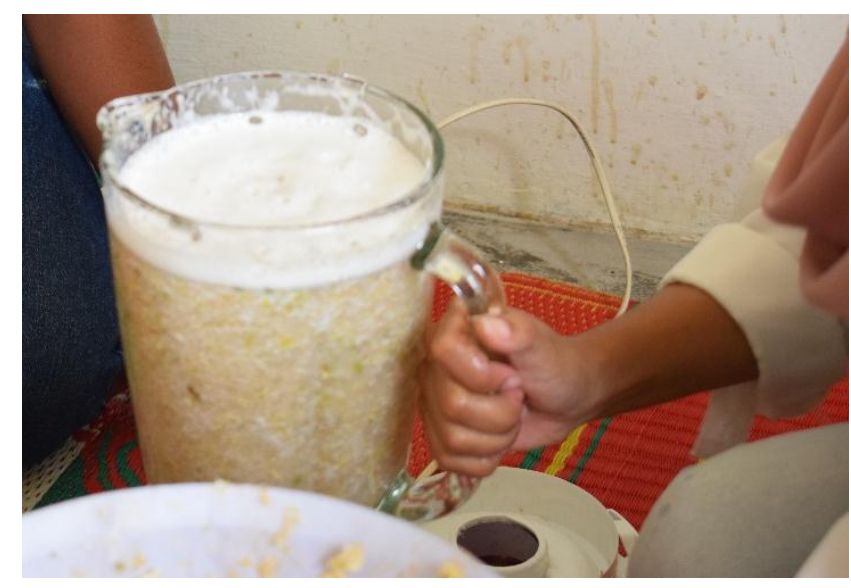

Gambar 1. Sari Kecambah Kacang Hijau.

Substrat yang mengandung gula (sebagai sumber carbon) dan kecambah kacang hijau (sebagai sumber nitrogen) di kondisikan pada $\mathrm{pH}$ asam (sekitar 4-4,5) atau yang sesuai dengan kebutuhan Acetobacter xylinum. Bahan baku utama atau air kelapa yang digunakan dalam pembuatan nata tersebut mengandung mineral dan asam organik, karena mineral dan asam organik akan digunakan sebagai komponen metabolisme dalam pembentukan kofaktor enzim ekstraseluler yang dihasilkan bakteri Asetobacter xylinum selama proses fermentasi (Pambayun, 2002).

Air kelapa sebagai substrat dalam pembuatan nata de coco sebelum digunakan terlebih dahulu disaring, yang bertujuan untuk memisahkan dari kotoran kotoran yang 
mungkin terbawa pada saat pengambilan. Hal ini penting untuk menjaga sanitasi dan hasil yang baik dari produk nata yang akan dihasilkan. Tahapan pemisahan ini dapat dilakukan dengan saringan biasa, bisa dilakukan sambil menakar jumlah air kelapa yang akan digunakan. Penyaringan dilakukan sebelum perebusan air kelapa. Perebusan air kelapa salah satunya bertujuan untuk merombak komponen makro menjadi mikro yang ada pada air kelapa. Hal ini bertujuan untuk memudahkan bakteri Acetobacter xylinum dalam memproduksi selulosa yang akan membentuk lembaran nata.

Proses pembuatan nata pada prinsipnya adalah fermentasi. Setiap proses pengolahan pangan yang berhubungan dengan mikroorganisme, hal yang penting dilakukan adalah sterilisasi. Sterilisasi dalam hal ini merupakan upaya untuk memberi kesempatan sebesar besarnya kepada bakteri Acetobacter xylinum untuk bekerja menghasilkan selulosa dan membentuk lembaran nata. Karena dengan sterilisasi mikroorganisme lain yang mungkin ada pada peralatan akan mati atau terhambat pertumbuhannya.

Sterilisasi merupakan proses mematikan atau menghambat pertumbuhan mikroorganisme pada suatu bahan atau peralatan. Sterilisasi pada nampan dan botol/wadah fermentasi nata, kertas penutup nata sangatlah penting. Hal ini juga sejalan dengan perebusan air kelapa yang salah satu tujuannya adalah untuk mematikan atau menghambat pertumbuhan mikroorganisme pada substrat tersebut. Jika sterilisasi tidak dikerjakan dengan benar, kegagalan dalam pembuatan nata juga sangat besar. Gambar 2 .

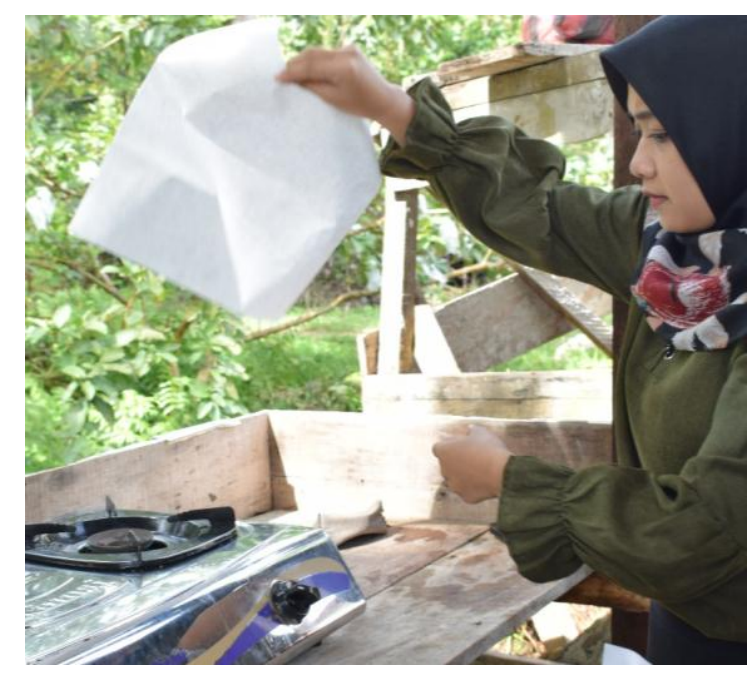

Gambar 2. Salah Satu Cara Sterilisasi Kertas

Substrat yang telah direbus dituang kedalam wadah fermentasi. Wadah fermentasi yang digunakan untuk membuat nata adalah nampan atau peralatan lain yang memiliki bidang datar (luas), karena yang diharapkan adalah lembaran nata yang melebar. Sedangkan wadah yang digunakan untuk membuat starter adalah botol atau benda yang tinggi dengan bidang datarnya kecil, karena yang diharapkan adalah airnya. Substrat yang telah dituang kedalam wadah fermentasi ditutup dengan kertas steril yang memiliki pori pori yang cukup untuk masuknya udara (oksigen). Winarno (2002) menjelaskan dengan adanya oksigen bakteri mencerna glukosa menjadi, $\mathrm{H}_{2} \mathrm{O}, \mathrm{CO}_{2}$ dan menghasilkan sejumlah ATP untuk pertumbuhannya. Substat ditunggu hingga dingin 
(lebih kurang $35^{\circ} \mathrm{C}$ ), selanjutnya ditambahkan dengan starter nata dan siap di fermentasi. Fermentasi diusahakan pada tempat yang tidak terkena cahaya matahari langsung dan pada tempat yang tidak terkena udara yang banyak. Gambar 3 berikut memulai fermentasi.

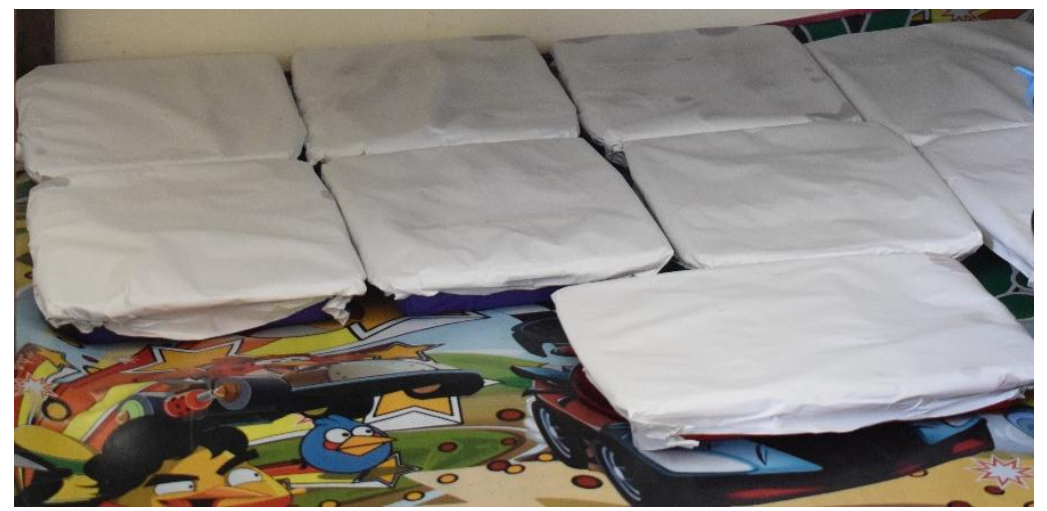

Gambar 3. Penyimpanan untuk Memulai Fermentasi

Nata yang sudah siap dipanen adalah nata yang berumur lebih kurang 8 hari, atau dengan ciri ciri: air sudah tidak banyak lagi, sudah terbentuk lapisan tebal nata. Palungkun (2001) menjelaskan lamanya waktu inkubasi menentukan terhadap nata yang dihasilkan, waktu inkubasi maksimal dalam pembuatan nata adalah selama 4 minggu, hal ini tergantung kepada substrat. Inkubasi merupakan proses yang dilewati setiap pengolahan pangan dengan cara di fermentasi. Waktu inkubasi optimum dalam pembuatan nata de coco adalah 7-10 hari. Gambar 4. Nata yang siap dipanen.

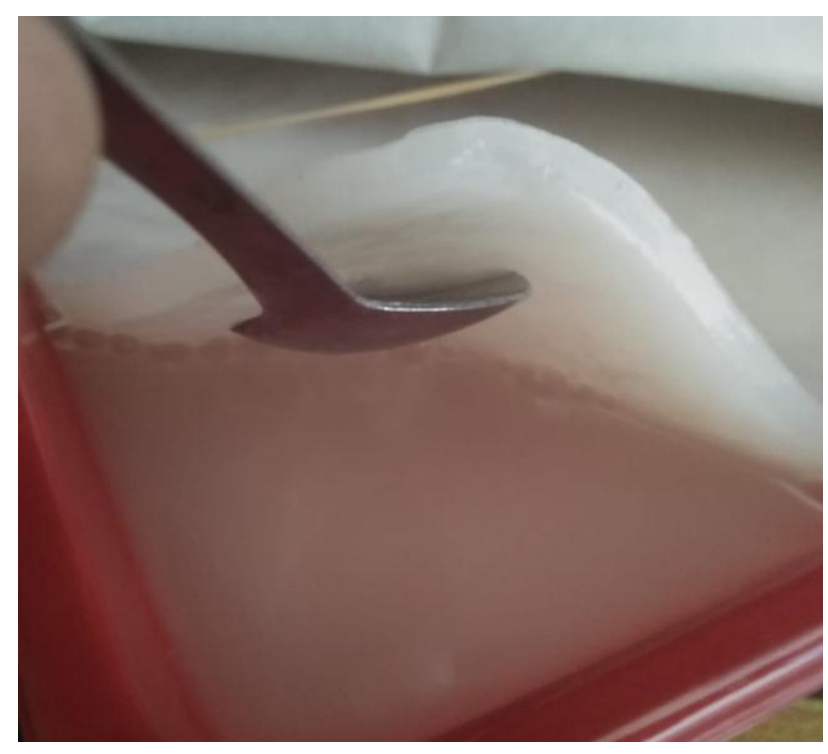

Gambar 4. Nata yang Siap Dipanen

Tahapan selanjutnya adalah pembuatan syrup nata. Nata yang telah dipanen direndam lebih kurang selama 2 hari dengan selalu mengganti air perendaman, 
kemudian direbus dan dipotong potong. Biasanya akan terbentuk lapisan tipis pada nata, lapisan tersebut dibuang sebelum nata dipotong. Pembuatan syrup nata dengan merebus nata pada air gula atau ditambahkan essence lain yang diizinkan (food grade) jika diinginkan.

\section{Evaluasi}

Evaluasi merupakan kegiatan yang bertujuan untuk pembinaan atau menentukan apakah kegiatan ini masih layak untuk dilanjutkan. Kegiatan ini sangat penting dilaksanakan untuk membina mitra supaya tidak gampang putus asa, karena diawal awal kegiatan sudah pasti banyak rintangan. Sehingga mitra harus tetap selalu dibimbing dan dibina, hingga menjadi mandiri.

\section{KESIMPULAN}

Mitra sangat tertarik dengan program yang diberikan dan berpartisipasi aktif selama kegiatan, pelaksanaan program berjalan sesuai dengan yang direncanakan. Pertambahan produk yang dihasilkan mitra diharapkan juga meningkatkan perekonomian mitra. Kegiatan ini diharapkan membawa dampak yang lebih baik bagi Jorong Bengke, karena mitra diharapkan juga bisa mentransfer keilmuan yang dimiliki.

\section{UCAPAN TERIMA KASIH}

Penulis mengucapkan terima kasih kepada LPPM Universitas Andalas yang telah memberi kesempatan penulis untuk melaksanakan kegiatan ini dengan hibah yang diberikan. Selain itu penulis juga mengucapkan terima kasih kepada mitra yang sangat proaktif demi keberhasilan pemograman ini.

\section{DAFTAR PUSTAKA}

Badan Pusat Statistik Padang Pariaman. 2017. Luas Lahan Tanaman Kelapa Padang Pariaman

Hidayat, N., C. Padaga dan S. Suhartini. 2006. Mikrobiologi Industri. Andi, Yogyakarta

Pambayun. 2002. Teknologi Pengolahan Nata de Coco. Kanisius, Yogyakarta.

Palungkun. 2001. Aneka Produk Olahan Kelapa. Swadaya, Jakarta

Sutarminingsih, C.H. 2004. Peluang Usaha Nata de Coco. Karnisius, Yogyakarta

Nasution, R.Y. 2016. Pengaruh Penambahan Ekstrak Kecambah Kedelai Sebagai Sumber Nitrogen Terhadap Sifat Fisik dan Kimia Nata de Soya. Skripsi. Jurusan Teknologi Hasil Pertanian Fakultas Teknologi Pertanian Universitas Andalas. 
Jurnal Hilirisasi IPTEKS

Vol. 1 No. 4, Desember 2018

Website. http://hilirisasi.lppm.unand.ac.id

e-ISSN: 2621-7198

Winarno, F. G. 2002. Kimia Pangan dan Gizi. Gramedia Pustaka Utama, Jakarta. 